\title{
Investigating correlations of local seismicty with anomalous geoelectrical, hydrogeological and geochemical signals jointly recorded in Basilicata Region (Southern Italy)
}

\author{
Gerardo Colangelo $\left({ }^{1}\right)$, Jens Heinicke $\left({ }^{2}\right)$, Vincenzo Lapenna $\left({ }^{3}\right)$, Giovanni Martinelli $\left({ }^{4}\right)$, \\ Marco Mucciarelli $\left({ }^{5}\right)$ and Luciano Telesca $\left({ }^{3}\right)$ \\ (') Ufficio Difesa del Suolo, Regione Basilicata, Potenza, Italy \\ $\left(^{2}\right)$ Saxon Academy of Sciences (SAW) at Leipzig, Research Group Bad Brambach/Freiberg, Germany \\ $\left(^{3}\right)$ Istituto di Metodologie per l'Analisi Ambientale (IMAA), CNR, Tito Scalo (PZ), Italy \\ (4) Agenzia Regionale Prevenzione e Ambiente (ARPA) dell'Emilia Romagna, Sezione di Reggio Emilia, Italy \\ $\left(^{5}\right)$ Dipartimento di Strutture, Geotecnica, Geologia Applicata all'Ingegneria (DiSGG), \\ Università degli Studi della Basilicata, Potenza, Italy
}

\begin{abstract}
This paper presents the preliminary results analysing the correlation between local seismicity and geoelectrical, hydrogeological and geochemical signals concomitantly recorded in Basilicata Region, one of the most seismically active areas in Southern Italy. The signals were recorded by two stations: Tito and Tramutola. Tito station measures vertically the Self-Potential field (SP) by an array of five no-polarizable electrodes equally spaced with the common electrode at $20 \mathrm{~m}$ depth as well as water-level, water-temperature and electrical-conductivity. Tramutola station measures self-potential signals in soil surface, gas flow and water temperature in a thermal-water well, as well as atmospheric barometric pressure and ambient temperature. Correlations were found between the sharp variability of the signals recorded by both stations and the seismic sequence that occurred on September 3 to 4, 2004, allowing us to link these anomalies with the tectonic evolution of the investigated area.
\end{abstract}

Key words self-potential records - gas flow - seismicity - fluids - precursor effects

\section{Introduction}

The understanding of possible seismic precursor phenomena is strictly linked to the vari-

Mailing address: Dr. Gerardo Colangelo, Ufficio Difesa del Suolo, Regione Basilicata, C.so Garibaldi 139, 85100 Potenza, Italy; e-mail: gerardo.colangelo@regione.basilicata.it ety of observed parameters and the formulation of accurate models of occurrence of possible precursory phenomena implies the need for multiparametric monitoring (Berkhemer et al., 1988).

Anomalous geophysical and geochemical patterns linked to stress and strain changes followed by earthquakes were recorded in many parts of the world including Greece, Japan, Germany, U.S.A., Russia, China, Taiwan, Armenia, Italy, etc. (e.g., Balassanian et al., 1997; Toutain and Baubron, 1999; Heinicke and Koch, 2000; Italiano et al., 2001; Tzanis and Vallianatos, 2001; Hayakawa and Molchanov, 2002; Uyeda 


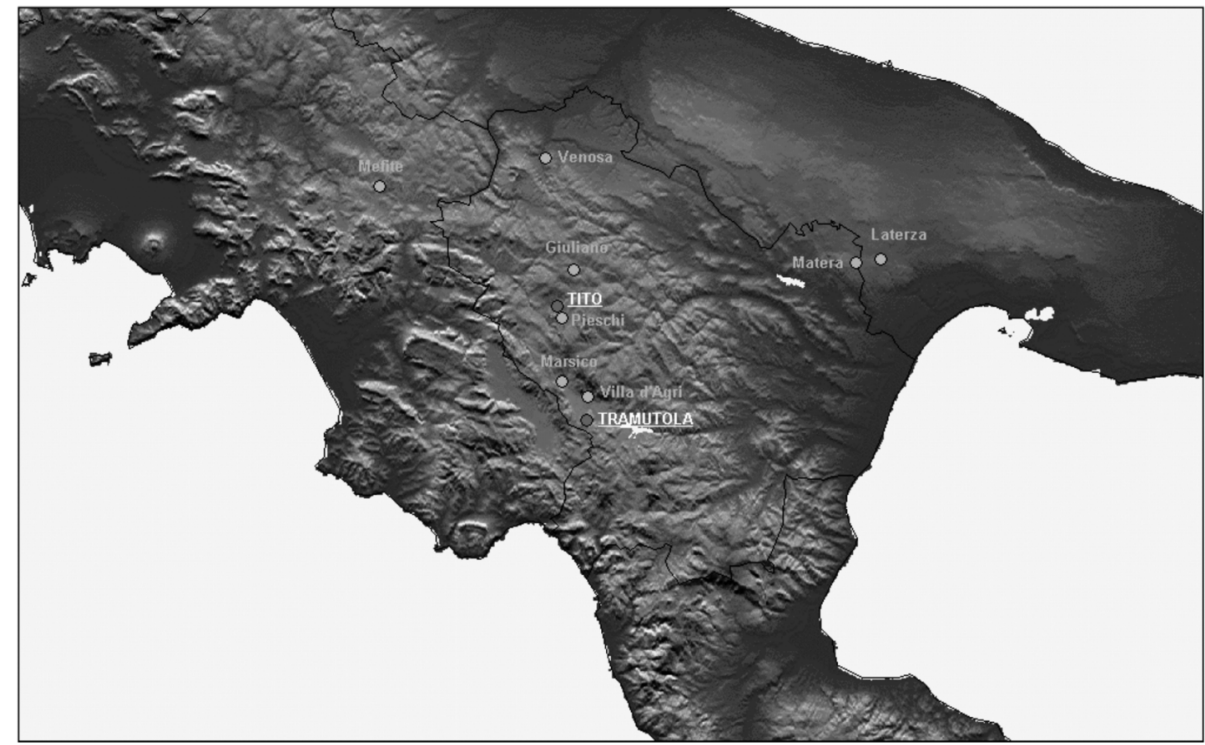

Fig. 1. Geophysical monitoring network in the Basilicata Region: the main test sites are Tramutola and Tito. Further stations are installed at Pieschi, Marsico, Villa d'Agri, Matera, Laterza, Giuliano, Venosa and Mefite.

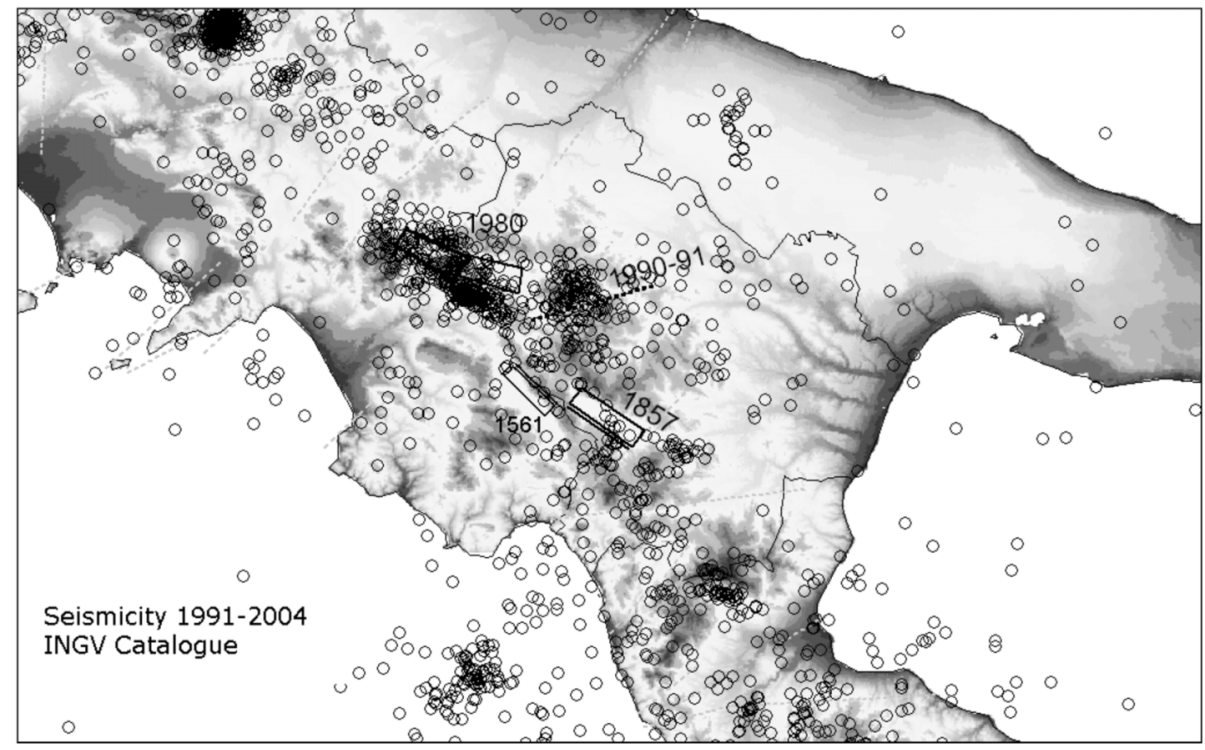

Fig. 2. Seismicity map of the investigated area (earthquakes with $M>1.8$ occurred between the years 19912004). The main seismogenetic areas are represented by Val d'Agri normal fault (mainshock 1857, I=XI MCS), Irpinia normal faults system (mainshock $1980, M_{s}=6.9$ ) and Potenza strike-slip fault (mainshock $1990 M_{d}=5.0$ ). 
and Park, 2002; Vallianatos et al., 2002; Crampin and Peacock 2003; Varotsos et al., 2003).

Transient physical phenomena affecting crustal structures involved in seismogenic processes may influence the circulation of deep-seated underground fluids as well as physical characteristics of hosting rocks (e.g., Scholz et al., 1973). Thus monitoring of deep circulating fluids has been widely utilized for researches oriented to the study of possible earthquake precursors (e.g., Ito et al., 1999; Toutain and Baubron, 1999). Analogous effort has been devoted to the study of possible geoelectric phenomena associated with earthquakes by means of adequate ground buried electrodes connected to a broadband amplifier (e.g., Corwin and Morrison, 1977).

Multiparametric monitoring experiments oriented to study possible seismic precursory phenomena have been set up in the U.S. (Bakun and Lindh, 1985) and Turkey (Berkhemer et al., 1988). The latest examples of seismically induced anomalies in fluid emission are presented in the issue of Pure Appl. Geophys. 163/4 (2006) and papers therein and Weinlich et al. (2006) and references therein.

A multiparametric monitoring experiment was set up in the Basilicata Region, Southern Apennines (fig. 1) with the purpose to better understand possible precursors of local seismic events (fig. 2). In particular typical parameters used for earthquake prediction research like gas flow rate, water temperature, water level, electric conductivity and self-potential in the ground were continuously monitored in both Tramutola and Tito test sites. Possible correlations among recorded parameters during September 2004 are discussed herein.

\section{Geological and seismological settings}

The Southern Apennines are a fold-andthrust belt built on from Late Oligocene to Pleistocene. The chain is mainly composed of Mesozoic-Cenozoic sedimentary cover from the Ligurian oceanic crust and the western passive margin of the Adriatic Plate, and of the Neogene-Pleistocene piggyback basin and foredeep deposits of the active margin. Recent shortening occurred at the belt front deforming Pleistocene sediments and volcanics whereas widely documented extension is still active along the Apennine axis. Major extensional features are located along the Tyrrhenian side of the chain. The belt is also affected by PlioceneQuaternary strike-slip faults (Schiattarella, 1998, and references therein).

From the Tyrrhenian Sea to the Adriatic (Apulian) Foreland, and from the top to the bottom of the wedge, the following tectonic units are observed (Pescatore et al., 1999, and references therein): 1) Jurassic to Oligocene polydeformed ophiolitic units, unconformably covered by syntectonic deposits, early Miocene in age (Ligurian units); 2) a carbonate platform unit (Campania-Lucania platform), whose age ranges from late Triassic to early Miocene; 3) several units mainly composed of deep-sea sediments, ranging from early Triassic to lowerMiddle Miocene; 4) a frontal imbricate fan made up of Cretaceous to lower Miocene deepsea marls, shales and sandstones, covered by Middle to Upper Miocene syntectonic deposits; 5) Pliocene to Pleistocene foredeep clastic deposits; 6) the Apulian carbonate platform, which has been partly incorporated at the base of the orogenic wedge, forming the less deformed foreland area toward the east.

The Tramutola station is located on the Il Monte fault as part of the NW-SE trending Monti della Maddalena fault zone which can be also mentioned as the Western Val d'Agri fault system (Maschio et al., 2005).

From the seismological point of view, the Campano-Lucano sector of the Southern Apennines Chain is one of the most active areas in the Mediterranean region. The area was hit by catastrophic earthquakes in 1466, 1561 and 1694. In February 1826 an earthquake, reaching up to VIII degree on the MCS scale (Alessio et al., 1995), hit the village of Tito where one of the geophysical monitoring station installed by IMAA-CNR is located (fig. 1). One of the most historically relevant events, the December 16, 1857 ( $I=$ XI MCS) normal-faulting earthquake (Mallet, 1862), occurred close to Marsico Nuovo village in Val d'Agri. On November 23, 1980, $\left(M_{s}=6.9\right)$, a large normal-faulting earthquake occurred in the nearby Irpinia area. Seis- 


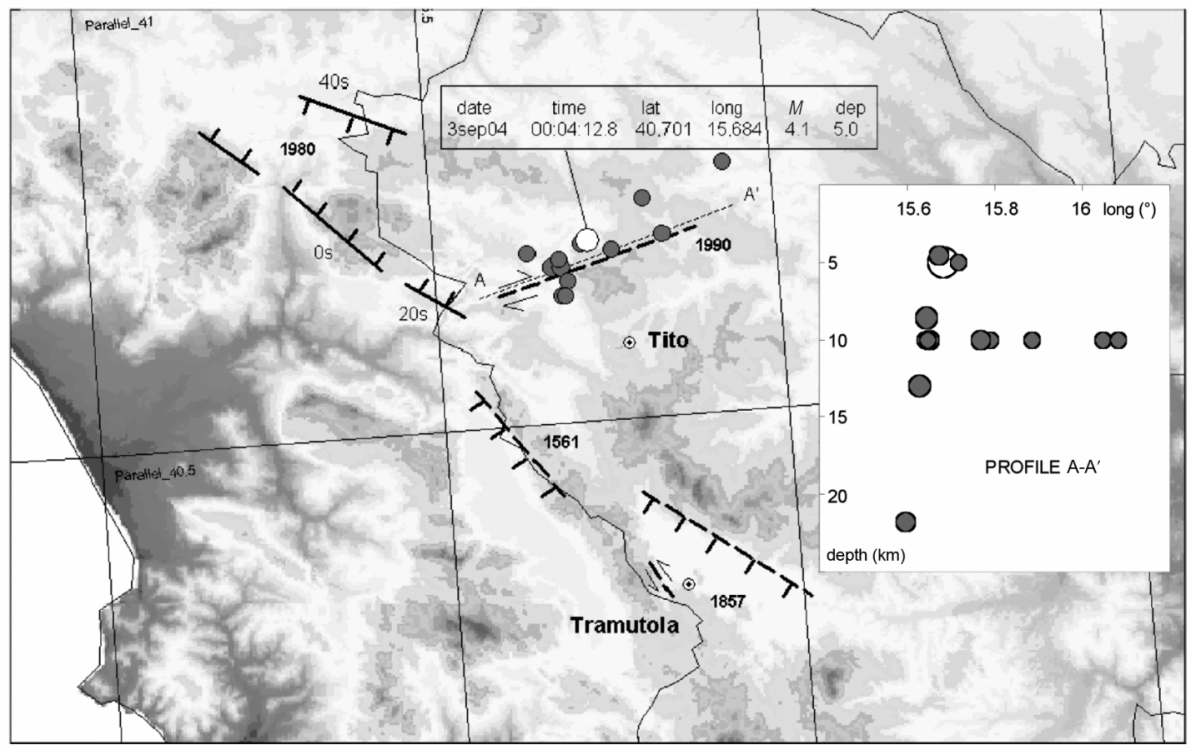

Fig. 3. Seismic sequence occurred on September 3-4, 2004, and hypocentres of the earthquakes along the profile A-A' on Potenza strike-slip fault. The map shows the normal fault system of Irpinia earthquake 1980 with the main subevents indicated as $0 \mathrm{~s}, 20 \mathrm{~s}$ and $40 \mathrm{~s}$. The solid lines represent the fault fragments activated in the investigated area which are mainly constrained by surface and levelling data. The dashed lines indicates the probably position of the faults and their dip.

mic activity occurred after the 1980 event consisting of medium intensity events $(M<5.5)$ located close to the border between Campania and Basilicata regions (Alessio et al., 1995). The May 5, $1990\left(M_{D}=5.0\right.$, ING-National Institute of Geophysics) and the May 26, 1991 $\left(M_{D}=4.7\right)$ earthquakes took place to the north of Potenza town (Tertulliani et al., 1992). These events have been generated by a strike-slip fault system with E-W direction, perpendicularly oriented toward the Apennines Chain (Ekström, 1994), located in such a way as to limit toward north and south two great seismogenetic faults that caused the 1857 Val d'Agri and 1980 Irpinia earthquakes respectively (fig. 2).

On April 18, 2002, a seismic sequence occurred along the northern side of the PergolaMelandro Basin. The $M_{w}=4.4$ main shock occurred at a depth of $9 \mathrm{~km}$, and was followed by a small number of $1.4 \leq M_{d} \leq 3.4$ aftershocks. The distribution of the earthquakes belonging to this sequence is concentrated within $3 \mathrm{~km}$ from the main shock. The mean depths of the shocks range between 4 and $15 \mathrm{~km}$, and the CMT solution for the main shock suggests a prevailing normal faulting mechanism with NE-SW direction of extension (see Cucci et al., 2004 for further details).

During the study period, a further meaningful seismic sequence occurred in the area of interest. On September 3, 2004 the sequence started with the main shock of magnitude $M_{L}=$ $=4.1$ in $5 \mathrm{~km}$ depth. 12 aftershocks followed the main event. Figure 3 shows the epicentral area of these events and their foci distribution along a NE-SW oriented fault zone. Profile A-A' sketched the depth distribution.

\section{Monitoring network}

The complex nature of the problem linked with geophysical anomalies in seismic areas suggests the design and installation of monitor- 
ing networks based on multiparametric remote stations able to measure geophysical parameters for a long time period.

In 2000 the Institute of Methodologies for Environmental Analysis (IMAA-National Council of Research, Potenza, Italy) installed a geophysical monitoring network to detect geoelectrical, geochemical and seismometric parameters in the Basilicata Region (Colangelo et al., 2004) (fig. 1).

In particular, this paper focuses on the monitoring activity in Tito and Tramutola stations:

i) the Tito station is equipped with a SP acquisition system, seismometric station and a hydrological/geochemical probe in a thermal-water well. During May 2004 a hole of $20 \mathrm{~m}$ was drilled to measure the SP field vertically. The array is characterized by five non-polarizable electrodes put in the ground equally spaced with the common electrode at $20 \mathrm{~m}$ depth. The seismometric station consists in a triaxial seismometer Mark L4-C-3D (1 Hz) with 24 bit digital acquisition unit and receiver PRAXS 10 GPS (trimble acutime RS422). The station is able to detect low-magnitude local earthquakes and teleseis- mic events. Electrical conductivity and water temperature were also measured in two drills.

ii) Tramutola station is located in an old 500 $\mathrm{m}$ deep well with strong methane and thermal water emission (fig. 4). The multiparameter station records SP signals on the soil surface, gas flow, water level of the discharge pool, air and water temperature, and barometric pressure. The recording interval is $10 \mathrm{~min}$. The gas flow from the well is $\mathrm{CH}_{4}$-dominated with portions of nitrogen. Italiano et al. (2001) reported seismically induced variations in the gas composition. The thermal water has a constant temperature of $27.8^{\circ} \mathrm{C}$, it is of $\mathrm{Na}-\mathrm{HCO}_{3}-\mathrm{Cl}$ type and is related to the carbonate dissolution process and subsequent cation exchange in the deep reservoir. The lack of sulphate in Tramutola water indicates little interaction with sulphate/evaporitic rocks in the circulation system (Italiano et al., 2001). The acquisition system consists in a datalogger (by Starlog, 16 bit resolution) connected with an acquisition card linked to the probes. The SP signals are measured by two $100 \mathrm{~m}$ length dipoles in two perpendicular directions.

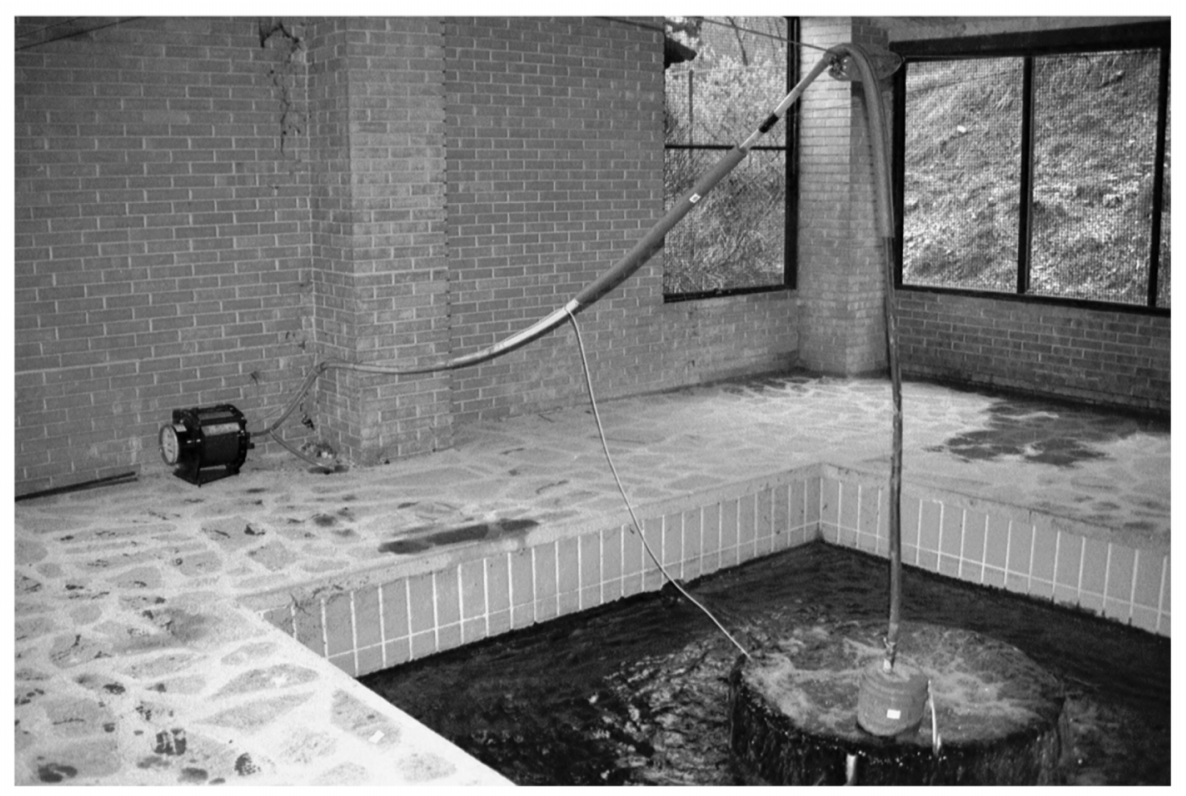

Fig. 4. Station of Tramutola with gas flow meter and the strong gas emission at the thermal-water well. 


\section{First results}

The knowledge of meteorological influences and fluctuations is important for geoelectrical, hydrogeological and geochemical data interpretation. Figure 5 shows the local barometric pressure and rain variations during the selected period of two months. No major rain events occurred in the area of interest during the seismic sequence, so we can exclude the influence of rain on the anomalous fluctuations of the recorded signals. The barometric pressure oscillations important for the interpretation of gas emission are not characterized by extreme maxima or minima values. High barometric pressure is responsible for low gas emission and vice versa (Heinicke and Koch, 2000).

The Tramutola station has existed for many years and gas flow anomalies were recorded in some cases before and after local seismic events (Colangelo et al., 2005). During the observation period, an anomalous gas flow behaviour occurred on August 20, 2004, likely related to local seismic events on August 18 $\left(M_{L}=2.7\right.$, in $17 \mathrm{~km}$ depth - probably too deep to generate this anomaly) or on August $24\left(M_{L}=\right.$ $=2.5$, in $8 \mathrm{~km}$ depth) (fig. 6). This anomaly confirms the seismogenic sensitivity of the Tramutola fluids in relation to local events, described by Colangelo et al. (2005). At the end of this anom-

Tramutola station: August-September, 2004

Barometric pressure
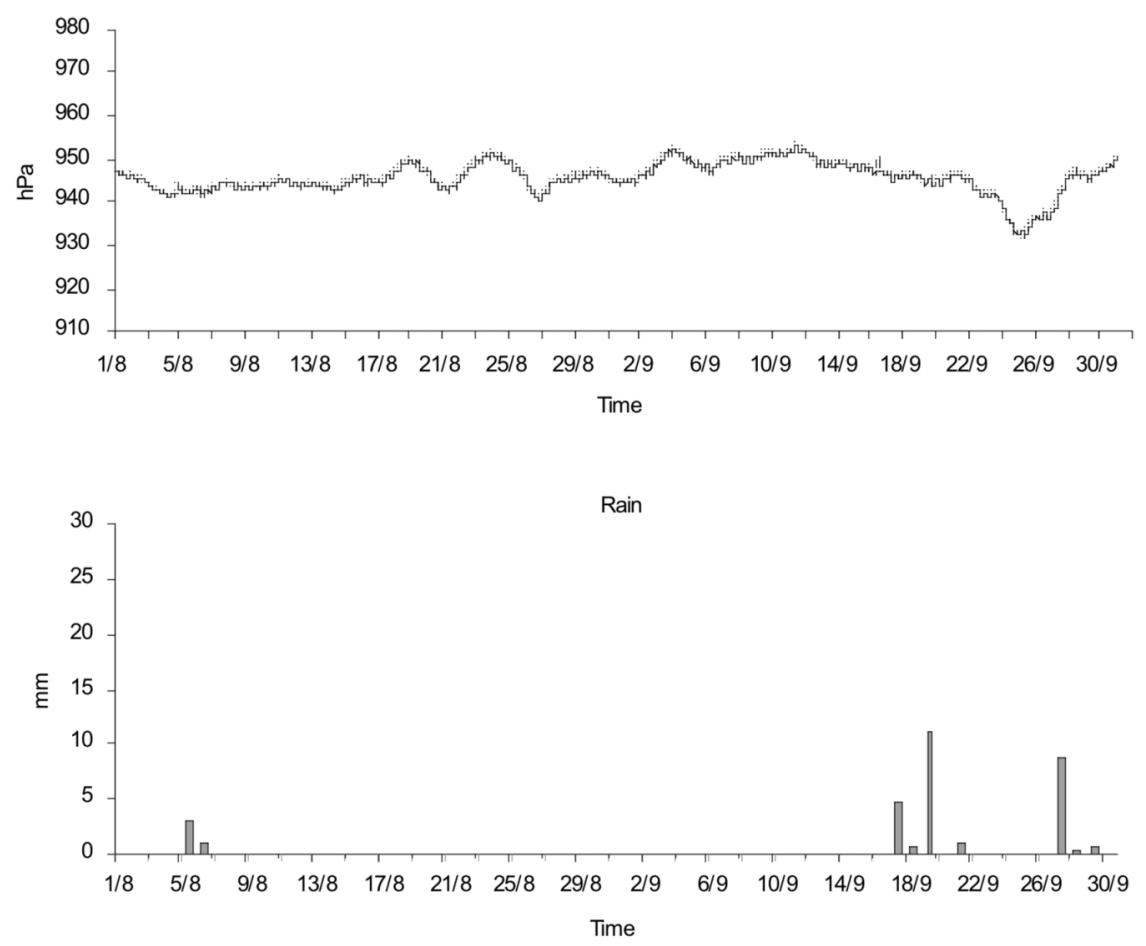

Fig. 5. Air pressure and rain recorded at the Tramutola station: August-September 2004. No strong barometric pressure variations and rain events occurred during the seismic sequence starting on September 3. 
Tramutola station: August-September, 2004

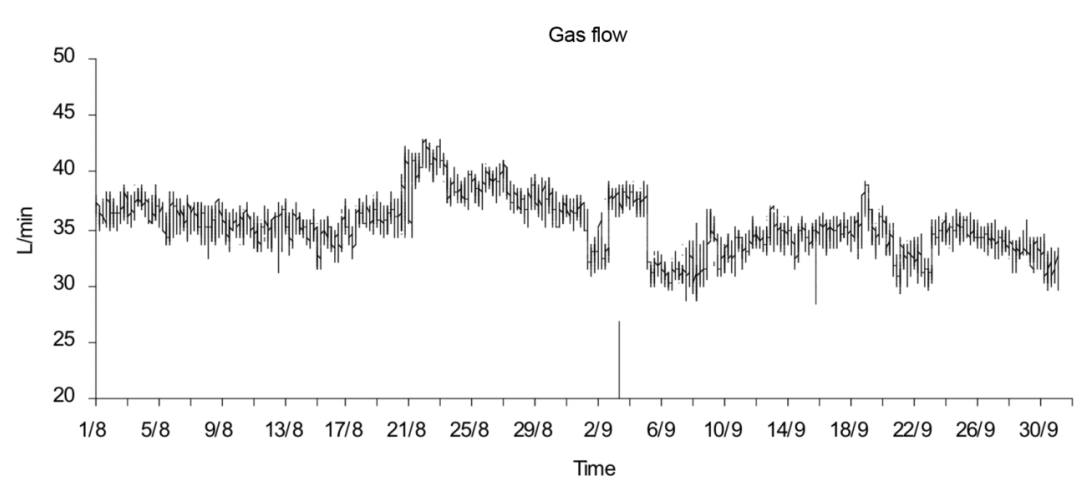

SP $100 \mathrm{~m}$ NS
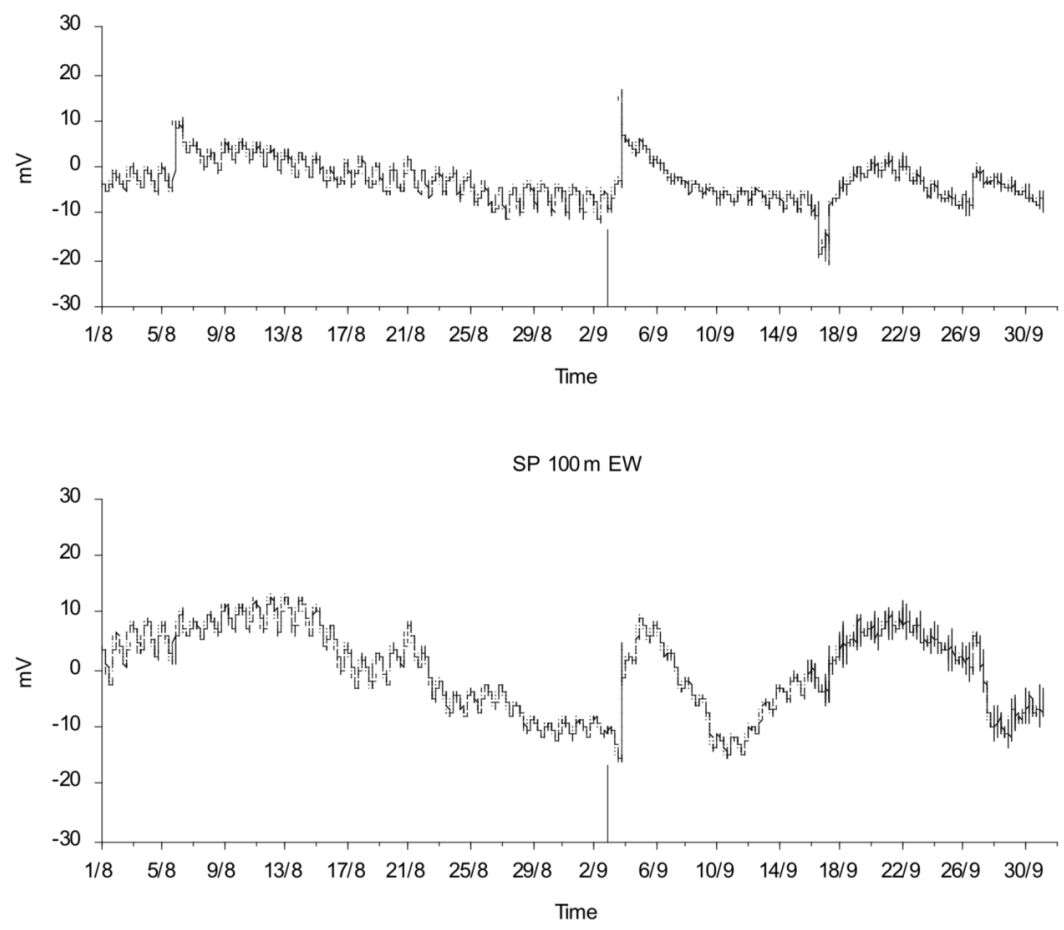

Fig. 6. Gas flow and self potential signals recorded at the Tramutola station between August-September 2004. A strong gas flow increasing was recorded before the seismic event on September 3 (grey bar), SP variations were post-seismic recorded.

aly, we have recorded a further significant anomaly started on September 1 . This anomaly is an important and extraordinary event in our records because it is the first hint for a laterally distrib- uted fluid variation due to seismogenic processes recorded at two sites: Tramutola and Tito. The anomaly was first recorded in the Tramutola gas flow as a sharp decreasing of $13 \mathrm{~h}$ followed by 

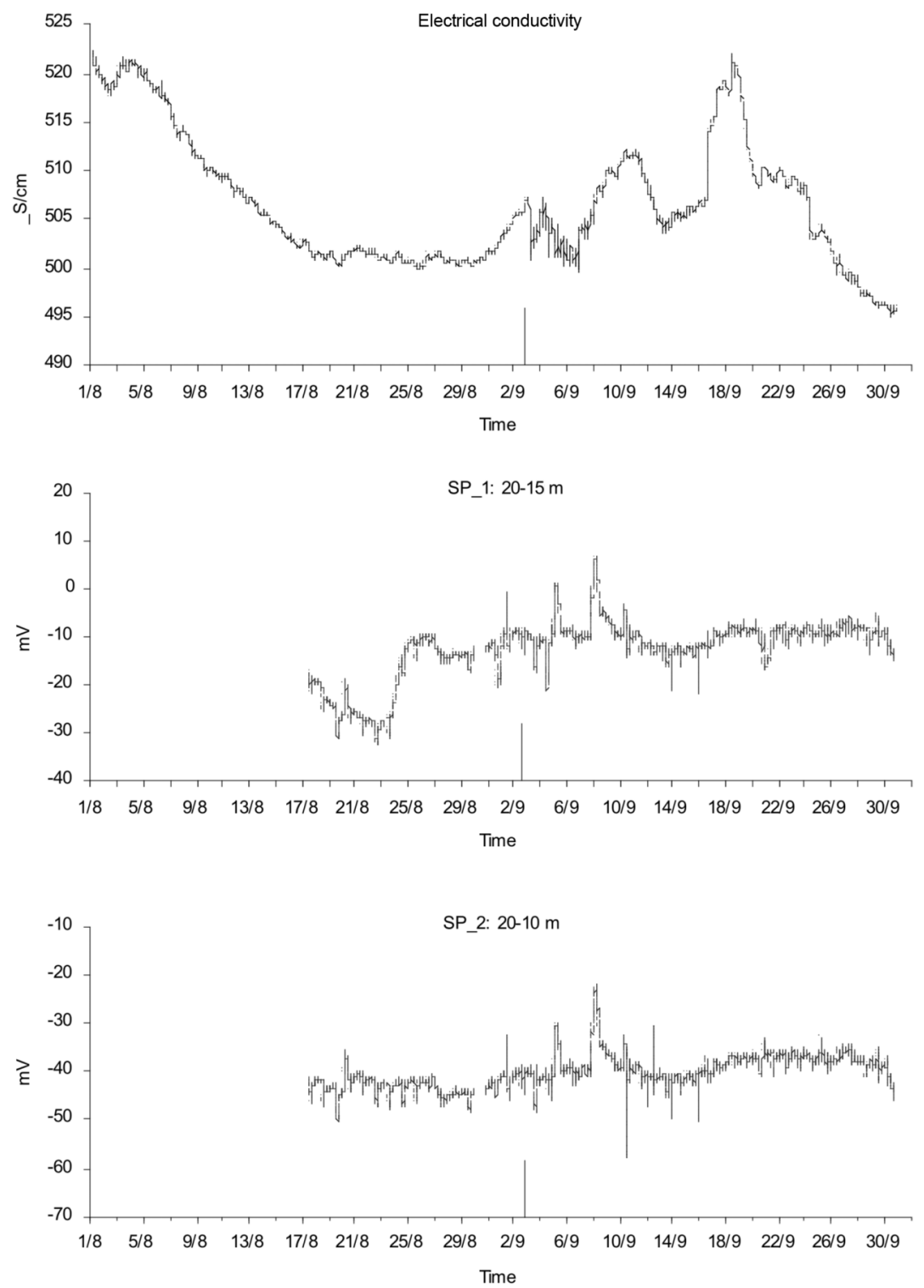

Fig. 7. Water conductivity and self potential signals recorded at the Tito station: August-September 2004. Sharp variation is present during and after seismic sequence on both parameters.

sharp increasing on September 2, $14 \mathrm{~h}$ before the strong September 3 event (fig. 9). Remarkable is further that this anomaly is identical in the kind of variation to a previous recorded anomaly on
November 20, 2001 which was related to an event in the same direction North of Tramutola (Colangelo et al., 2005). Surprisingly is the same behaviour: sharp drop down followed by a sharp 
increasing to a slightly increased higher level of gas flow. The temporal difference between increasing and the following event is $8 \mathrm{~h} 2001$ and $13 \mathrm{~h}$ 2004. The distances between epicentre and station are in a similar relation: $25 \mathrm{~km}$ in 2001 and $42 \mathrm{~km}$ in 2004. This could be a chance relation. A further argument could be based on a longer stress accumulation period of two/three weeks before the main shock with the consequence of a different energy release. The magnitudes were 20012.8 and 2004 4.1.

The increased gas flow stopped at the end of the seismic sequence on September 5.

At the same time, anomalies of the SP signal were also recorded (fig. 6) at Tramutola. Both dipole directions E-W and N-S show a sharp step in their record on September 3 at 3 p.m., $15 \mathrm{~h}$ after the first main shock. No rain was detected in that time, as mentioned before.

The behaviour of the electric conductivity recorded at the Tito station, $30 \mathrm{~km}$ north of Tramutola, shows an anomalous variation at the beginning of the seismic sequence. This co-seismic anomaly with a duration on the next 4 days is characterized by short-term fluctuations (fig. 7). We assume that the first main shock changed the conduit system and therefore the mixture of different aquifers in the well. Probably less mineralised fluid penetrated into this water aquifer during that period. The long-term trend was not influenced, only rain shows an important role here, as visible e.g., on September 16/18, 2004.

Concomitantly significant variations in the SP values were also recorded in the Tito station

Tito station: August-September, 2004
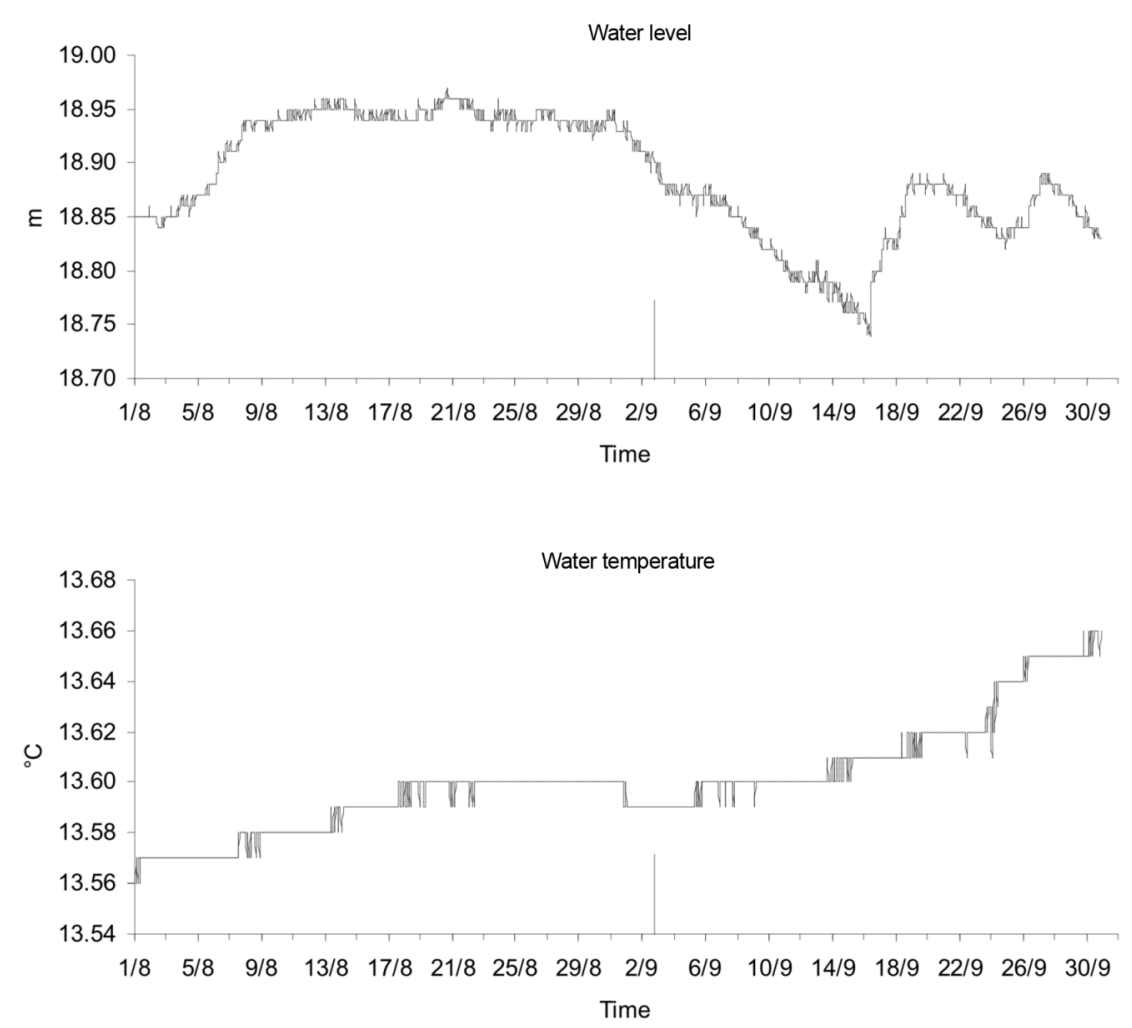

Fig. 8. Water level and water temperature recorded at the Tito station: August-September 2004. 
August 29,2004-September 6, 2004

Gas flow (Tramutola station)
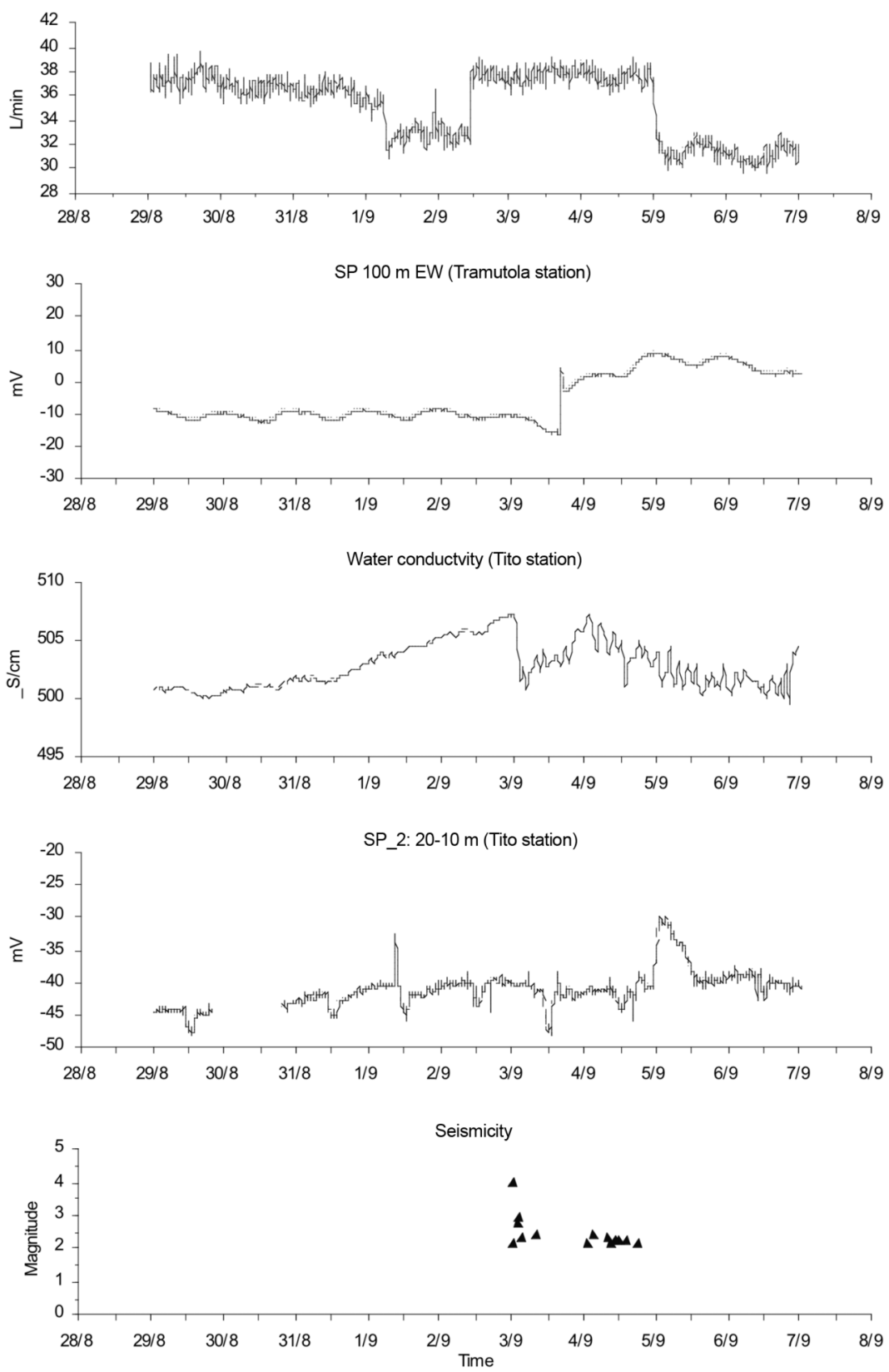

Fig. 9. Zoom on gas flow, SP and electrical conductivity signals recorded at the Tramutola and Tito stations and the local seismicity between August 29, to September 6, 2004. An anomalous behaviour in both locations were recorded before and after the seismic sequence. 
(fig. 7). SP signals measured by electrodes at 15 $\mathrm{m}$ and $10 \mathrm{~m}$ depth show anomalous spiky values 2 to 5 days after the occurrence of the seismic event. Probably the time gap between the occurrence of the earthquake and the time of appearance of the anomalous values is due to a reduced transport of fluids and, in particular, of electrolytes in the surrounding groundwater and fissure zone supported by a concomitant water level decreasing.

The water level is characterized by a slight decrease of about $10 \mathrm{~cm}$ after the occurrence of the seismic event, lasting almost two weeks (fig. 8). This decreasing trend ended on September 16/17, 2004 because of the rain. The water temperature does not show any correlation with the earthquake, because the slight increase is mainly due to a seasonal effect.

\section{Discussion}

Meteorology and local stress variations influence the variability of the recorded signals at each station (e.g., Colangelo et al., 2005), in particular the stress variations can be recognized by local seismicity or as pore pressure variations in active fault zones. Geoelectrical, hydrogeological or geochemical anomalies can be recorded due to this geodynamically influenced fluid transport. Furthermore, during a short-term period in which the $M_{L}=4.1$ earthquake of September 3, 2004 occurred, the signals recorded at two stations (Tramutola and Tito) showed concomitantly an anomalous behaviour (fig. 9). We assume that the accumulated stress and its relaxation in the fault zone induced pore pressure diffusion or transport processes before, during and after the events. The registration of different phenomena and parameters can be interpreted as results of stress-induced fluid migration. Remarkable is the occurrence of the first anomaly in the gas flow in the station furthest from the epicentre. Contact with the deep fluid reservoirs is an important constraint for that «precursor» effect. The coincidence of groundwater/fluid flow direction and strike direction of the Val d'Agri Valley (NW-SE) with an extensional motion could be the reason for a stress driven fluid anomaly in these fault lines (Gudmundsson, 2000).

\section{Conclusions}

A singular seismic activity caused an anomalous fluid migration recorded in two different stations. The recorded anomalies occurred concomitantly in the two stations indicating the spatial distribution of stress driven fluid migration before strong shocks along the fault zone. The fluid-filled fracture system can be considered the transport path of these stress variations, which is probably transmitted due to pore pressure diffusion processes. The results confirm the previous recorded anomalies presented in Colangelo et al. (2005).

\section{Acknowledgements}

The authors are grateful to G. Strauch and F. Vallianatos whose suggestions improved the present paper.

\section{REFERENCES}

Alessio, G., F. Esposito, A. Gorini and S. Proofed (1995): Detailed study of the Potentino seismic zone in the Southern Apennines, Tectonophysics, 250, 113-134.

BAKUN, W.H. and G.G. LINDH (1985): The Parkfield, California, earthquake prediction experiment, Science, 229, 619-624.

Balassanian, S., A. Mouradian, A. Sahakian, S. KalinIN, M. BABAYAN and A. Pogossian (1997): The investigations of electromagnetic precursors to earthquakes in Armenia, Ann. Geofis., XL (2), 209-225.

Berkhemer, H., J. Zschau and O. Ergunay (1988): The German-Turkish Project on earthquake prediction research, concept and first results, in Proceedings of the ECE/UN Seminar on Prediction of Earthquakes, edited by C.S. Olivera, Lisbon, 579-601.

Colangelo, G., M. Balasco, V. Lapenna and L. Telesca (2004): Design and installation of a monitoring network to investigate the correlations between geoelectrical fluctuations and seismicity of Basilicata Region (Southern Italy), Phys. Chem. Earth, 29, 313-320.

Colangelo, G., J. Heinicke, U. Koch, V. Lapenna, G. MARTINELLI and L. TELESCA (2005): Results of gas flux records in the seismically active area of Val d'Agri (Southern Italy), Ann. Geophysics, 48 (1), 55-63

Corwin, P.F. and H.F. MorRISON (1977): Self-potential variations preceding earthquakes in Central California, Geophys. Res. Lett., 4, 171-174.

Crampin, S. and S. Peacock (2003): Seismic Evidence for fluid-driven deformation, J. Geodyn., 36, 67-77.

Cucci, L., S. Pondrelli, A. Frepoli, M.T. Mariucci and M. MoRo (2004): Local pattern of stress field and seismogenic sources in the Pergola-Melandro Basin and 
the Agri Valley (Southern Italy), Geophys. J. Int., 156 (3), 575-583.

EKSTRÖM, G. (1994): Teleseismic analysis of the 1990 and 1991 earthquakes near Potenza, Ann. Geofis., XXXVII (6), 1591-1599.

Gudmundsson, A. (2000): Active fault zones and groundwater flow, Geophys. Res. Lett., 27, 2993-2996.

Hayakawa, M. and Molchanov (2002): Seismo Electromagnetics, Lithosphere-Atmosphere-Ionosphere Coupling, edited by M. HaYaKaWa and O.A. Molchanov (Terrapub, Tokyo, Japan), pp. 477.

HeINicke, J. and U. Koch (2000): Slug flow - A possible explanation for hydrogeochemical earthquake precursors at Bad Brambach, Germany, Pure Appl. Geophys., 157, 1621-1641.

Italiano, F., M. Martelli, G. Martinelli, P.M. Nuccio and M. PAternoster (2001): Significance of earthquake-related anomalies in fluids of Val d'Agri (Southern Italy), Terra Nova, 13, 249-257.

Ito, T., K. Nagamine, K. Yamamoto, M. Adachi and I. KaWABE (1999): Preseismic hydrogen gas anomalies caused by stress-corrosion process preceding earthquakes, Geophys. Res. Lett., 26, 2009-2012.

Mallet, R. (1862): The Great Neapolitan Earthquake of 1857. The First Principle of Observational Seismology, London, vol. I, pp. 431, vol. II, pp. 339.

Maschio, L., L. Ferranti and P. Burrato (2005): Active extension in Val d'Agri area, Southern Apennines, Italy: implications for the geometry of the seismogenic belt, Geophys. J. Int., 162, 591-609.

Pescatore, T., P. Renda, M. Schiattarella and M. TraMUTOLI (1999): Stratigraphic and structural relationship between Meso-Cenozoic Lagonegro Basin and coeval carbonate platforms in Southern Apennines, Italy, Tectonophysics, 315, 269-286.

Schiattarella, M. (1998): Quaternary tectonics of the Polli- no Ridge, Calabria-Lucania boundary, Southern Italy, in Continental Transpressional and Transtensional Tecton$i c s$, edited by R.E. HoldSwORTH, R.A. STRACHAN and J.F. Dewey, Geol. Soc. Spec. Publ. 135, 341-354.

Scholz, C.H., L.R. Sykes and Y.P. AgGarwal (1973): Earthquake prediction: a physical basis, Sciences, 181, 803-809.

Tertulliani, A., M. Anzidei, A. Maramai, M. Murru and F. RiguzzI, (1992): Macroseismic study of the Potenza (Southern Italy) earthquake of 5 May 1990, Nat. Hazards, 6, 25-38.

ToutAin, J.P. and J.C. BAUBRON (1999): Gas geochemistry and seismotectonics: a review, Tectonophysics, 304, 1-27.

TZanis, A. and F. Vallianatos (2001): A critical review of electric earthquake precursors, Ann. Geofis., 44 (2), 429 460.

UYEDA, S. and S. PARK (2002): Recent investigations of electromagnetic variations related to earthquakes, $J$. Geodyn., 33, 377-570.

Vallianatos, F., V. Lapenna, V. TRoyian, N. Smirnova, Y. KopytenKo, V. KoREPANOV and T. MATIASHVILI (2002): Study of the ULF electromagnetic phenomena related to earthquakes: strategy of the SUPRE project, in Seismo Electromagnetics Lithosphere-Atmosphere-Ionosphere Coupling, edited by HaYAKAWA, M. and MoLCHANOV (Terrapub, Tokyo, Japan), 437-442.

VArotsos, P., N. SARLis and E. Scordas (2003): Electric field that «arrive» before the time derivative of the magnetic field prior to major earthquakes, Phys. Rev. Lett., 91, 148501

Weinlich, F.H., E. Faber, A. Bouskova, J. Horalek, M. Teschner and J. Poggenburg (2006): Seismically induced variations in Marianske Lazne fault gas composition in the NW Bohemian swarm quake region, Czech Republic - A continous gas monitoring, Tectonophysics, 421, 89-110. 